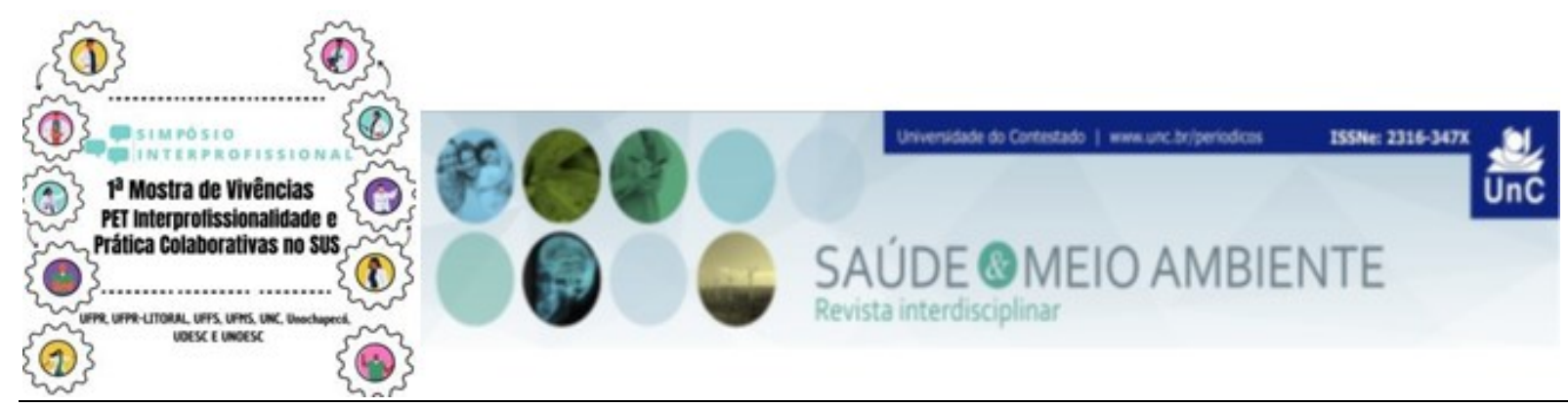

\title{
ESTUDO DA SÍNDROME RESPIRATÓRIA AGUDA GRAVE NO DISTRITO SANITÁRIO DO PORTÃO NO PRIMEIRO SEMESTRE DE 2019: RELATO DE VIVÊNCIA DO PET ${ }^{1}$
}

\author{
Projeto 88 \\ Luana Leonardo Garcia ${ }^{2}$ \\ Leiliane Alencar dos Santos ${ }^{3}$ \\ Helene Nicolle Pardo 4 \\ Natália Murai Guedes ${ }^{5}$ \\ Gabriella Reis ${ }^{6}$ \\ Gislaine Cristina dos Santos ${ }^{7}$ \\ Karin Regina Luhm ${ }^{8}$ \\ Fernanda Moura D'Almeida Miranda ${ }^{9}$
}

\section{RESUMO}

Introdução: A Vigilância Epidemiológica (VE) tem como enfoque um conjunto de ações que atuam na detecção, promoção, organização e acompanhamento de saúde, tanto individual como coletivo. Dispondo, assim, do papel de produção e disseminação de dados epidemiológicos sobre determinadas doenças (Ministério da Saúde, 2019). Essas informações disseminadas são fundamentais para a tomada de decisão com

\footnotetext{
${ }^{1}$ Fonte de financiamento: Programa de Educação pelo Trabalho para a Saúde - PET Saúde/Interprofissionalidade 2019-2021 (Edital no 10 de 23 de julho de 2018, Ministério da Saúde/Secretaria de Gestão do Trabalho e da Educação na Saúde).

2 Aluna do Curso de Farmácia, bolsista do Subgrupo Vigilância em Saúde - PET Saúde Interprofissionalidade Curitiba. Universidade Federal do Paraná. Paraná. Brasil. E-mail: cwlkluana@gmail.com

${ }^{3}$ Residente de Terapia Ocupacional em Saúde da Família. Universidade Federal do Paraná, ex bolsista do Subgrupo Vigilância em Saúde - PET Saúde Interprofissionalidade Curitiba. Paraná. Brasil. E-mail: enailiel2012@gmail.com

${ }^{4}$ Aluna do curso de Enfermagem, ex bolsista do Subgrupo Vigilância em Saúde - PET Saúde Interprofissionalidade Curitiba. Universidade Federal do Paraná. Paraná. Brasil. E-mail: helene.pardo@ufpr.br

${ }^{5}$ Aluna do curso de Enfermagem, ex bolsista do Subgrupo Vigilância em Saúde -PET Saúde Interprofissionalidade Curitiba. Universidade Federal do Paraná. Paraná. Brasil. E-mail: naty.murai13@gmail.com

${ }^{6}$ Aluna do curso de Medicina, bolsista do Subgrupo Vigilância em Saúde - PET Interprofissionalidade Curitiba. Universidade Federal do Paraná. Paraná. Brasil. E-mail: gabriellaakings@gmail.com

${ }^{7}$ Enfermeira, Servidora Pública da Secretaria Municipal de Saúde de Curitiba. Preceptora do Subgrupo Vigilância em Saúde. Secretária Municipal de Saúde de Curitiba. Paraná. Brasil. Email:gisaenfermeira10@gmail.com

${ }^{8}$ Professora Adjunta do Departamento de Saúde Coletiva. Professora Tutora. Universidade Federal do Paraná. Paraná. Brasil. E-mail: karinluuhm@ufpr.br

${ }^{9}$ Professora Adjunta do Departamento de Enfermagem. Coordenadora do Subgrupo Vigilância em Saúde. Universidade Federal do Paraná. Paraná. Brasil. E-mail: fmdmiranda@gmail.com
} 
relação ao comportamento da doença ou agravo. Objetivo: Elaborar um boletim epidemiológico com dados do primeiro semestre de 2019 relativos às notificações de Síndrome Respiratória Aguda Grave (SRAG) do Distrito Sanitário do Portão (DSPR). Métodos: Pesquisa documental, realizada por estudantes de diferentes cursos da área da saúde e preceptores do PET Saúde Interprofissionalidade - grupo Vigilância em Saúde. Para coleta de dados das notificações de SRAG foi utilizado o sistema SINAN-Net (Sistema de Informação de Agravos de Notificação) e planilhas do Excel (SINAN, 2019). As notificações de SRAG foram preenchidas em hospitais e UPAs (Unidades de Pronto-Atendimento). O boletim focou nos residentes da área de abrangência do DSPR, este que é um dos 10 distritos da Cidade de Curitiba, no qual abrange 7 Unidades de Saúde da região (Santa Amélia, Estrela, Santa Quitéria, Parolin, Vila Guaíra, Santos Andrade e Santa Quitéria II). Resultados: Durante o primeiro semestre de 2019, o DSPR coletou 62 notificações referentes à SRAG, as quais foram classificadas em: 34 notificações de SRAG não especificada (55\%), 7 notificações de SRAG por influenza A H1N1 (11\%) e 21 notificações de SRAG por outros vírus respiratórios (34\%). Das 62 notificações, apenas 7 tiveram o desfecho de óbito consequente da doença, sendo que 4 eram considerados como SRAG nãoespecificado e 3 casos identificados como causa da influenza A. Conclusão: Analisando os dados percebe-se a importância do papel da VE e dos diferentes profissionais que a compõem no monitoramento, avaliação, registro e acompanhamento das notificações, em conjunto do PET Saúde Interprofissionalidade possibilitando, assim, gerar dados que impulsionam ações de controle destas doenças, fortalecendo o vínculo entre ensino, saúde e comunidade.

Palavras-chave: Síndrome Respiratória Aguda Grave. Monitoramento Epidemiológico. Vigilância em Saúde Pública.

\section{REFERÊNCIAS}

1. Ministério da Saúde (BR), Secretaria de Vigilância em Saúde. Guia de Vigilância em Saúde. (3a Ed.). Brasília (DF). Ministério da Saúde; 2019. [Material Impresso].

2. Sistema de Informação de Agravos de Notificação (SINAN BR). Sistema de Informação de Vigilância Epidemiológica de Gripe/SIVEP-Gripe. Notificações Registradas: banco de dados; 2019. [Acesso restrito] 